\title{
Solkongens analfistel
}

Ludvig 14 av Frankrike (1638-1715) - Solkongen - utviklet i 1686 en perianal abscess, som ved gjentatte mislykkede fors $\emptyset \mathrm{k}$ på behandling, blant annet ved bruk av glødende jern, utviklet seg til en analfistel. Legene var maktesløse, og etter flere måneders betenkningstid ble kongen operert - med vellykket resultat. Kirurgene var den gang underlagt indremedisinerne, men fikk ved hjelp av kongen bedre arbeidsforhold og større prestisje. Med iherdig innsats fra senere fremragende franske kirurger og kongelig støtte så l'Académie Royale de Chirurgie (det kongelige akademi for kirurgi) dagens lys i 1731. Senere fulgte en reorganisering av den medisinske utdanningen i Frankrike, med etablering av institusjoner der man samlet undervisningen innen indremedisin og kirurgi.

I artikkelen Medisinens kirurgisering og etableringen av en norsk legeskole $i 1814$ av Per Haave, publisert i Tidsskriftet i 2009 (1), blir den franske kirurgireformen fremhevet som rollemodell for Danmark-Norge. Da er det nærliggende å spørre hvordan de franske kirurgene ble foregangsmenn?

Paris var fra slutten av det 17. århundre ansett som det ypperste senter for anatomi og kirurgi (2). Dette skyldtes ikke minst at byens kirurger fikk sjansen til å utføre store og viktige operasjoner, at de hadde tilgang til nye instrumenter, og at de hadde god kunnskap om anatomi ut fra disseksjon av et stort antall kadavre (2).

Men også Ludvig 14, som ved sitt personlige behov for kirurgisk hjelp og mot til å utsette seg for farlige kirurgiske inngrep, skal ha en stor del av æren for at Paris og Frankrike ble pionerer innen feltet. Han ga fransk kirurgi den nødvendige drahjelp til å komme ut av indremedisinernes skygge og slik kunne etableres som et seriøst, selvstendig fag.

\section{Analfistelen}

Vinteren 1686 utviklet Ludvig en tumor i skrittet. Denne er behørig beskrevet av hans livlege Antoine Daquin (1629-96): «15. januar klaget Hans Majestet over en liten klump i skrittet, to fingerbredder foran analåpningen, som ikke ga smerter ved berøring, uten rødme og uten pulsering» (3).

Kulen skyldtes sannsynligvis betennelse $i$ en av kjertlene i området. Kjertelbetennelse skal ha vært vanlig på 1600-tallet (4). Kongens leger begynte behandlingen med diverse omslag, blant annet sukkeromslag. Da det utviklet seg en verkebyll (perianal abscess), ble det stukket hull for at pusset skulle kunne tømmes ut. Det ble på sett og vis mulig å tørke ut såret ved å legge på kompresser dyppet $i$ avkok fra diverse blader og fra roser kokt i rødvin (burgundervin). Legene klarte også å fylle det hulrommet som var blitt dannet ved å sprøyte inn ulike stoffer, en for kongen svært smertefull prosess.

Hans Majestet ble mer og mer vred over verkebyllen, som stadig rant og som tvang ham til å skifte klær både to og tre ganger per dag etter middag (5). Plagene fortsatte gjennom flere måneder. Smerten var uttalt, men hver gang han følte seg bedre, fortsatte legene med sine behandlinger, bestående av klyster og avføringsmidler, noe som bidro til å forverre miseren (5). Etter fire måneder mistenkte man at det hadde dannet seg en fistel. De stadige behandlingene med brennende jern hadde nok også medvirket til å lage krateret større.

Etter å ha slitt med smerter og annet ubehag i flere måneder skjønte kongen at legene var maktesløse. Han besluttet å la seg operere. I mellomtiden isolerte han seg i sin leilighet i Versailles, sur og lei. Til og med hoffet så lite til ham. Han måtte oppgi ridningen, og de gangene man kunne se ham ute i hageanlegget, satt han i bærestol.

\section{Opptakten til operasjonen}

Ingen kirurg våget å gå løs på Solkongen uten å ha øvd seg på forhånd. Den store operasjonen ble planlagt $\mathrm{i}$ detalj og i all hemmelighet. Kun krigsministeren Louvois (1641-91), Ludvig 14s nye, hemmelige kone Madame de Maintenon (1635-1719), hans skriftefar père La Chaise (François de La Chaise (1624-1709) - den berømte kirkegården i Paris har fått navn etter ham og kongens leger var innviet i planene (fig 1). Kronprinsen ble ikke informert.

Det har vært uklart hvem som var forsøkskaniner, men pasienter fra sykehus $\mathrm{i}$ byen Versailles har vært nevnt (6). Historikere har forgjeves forsøkt å finne ut hvordan det gikk med dem - eller rettere sagt hvor mange som døde - men uten resultat. Etter sigende skal man ha begravet de døde ved soloppgang, uten å kime med kirkeklokkene, slik at ingen skulle få nyss i hva som var skjedd. Man kjenner til én som visstnok skal ha overlevd (4).

Charles-François Félix (junior) (16351703), kongens førstekirurg, hadde ikke utført denne type operasjon tidligere, men tilegnet seg førsteklasses erfaring i de

\section{Ellen Jørum}

ellen.jorum@medisin.uio.no

Klinisk nevrofysiologisk seksjon

Nevrologisk avdeling

Oslo universitetssykehus, Rikshospitalet

Engelsk oversettelse på www.tidsskriftet.no

HOVEDBUDSKAP

Fransk kirurgi fikk høy prestisje etter et vellykket inngrep på Ludvig 14, og det ble opprettet egne kirurgiske utdanningsinstitusjoner

I 1808 ble det medisinske fakultet reetablert, med undervisning i både medisin og kirurgi 


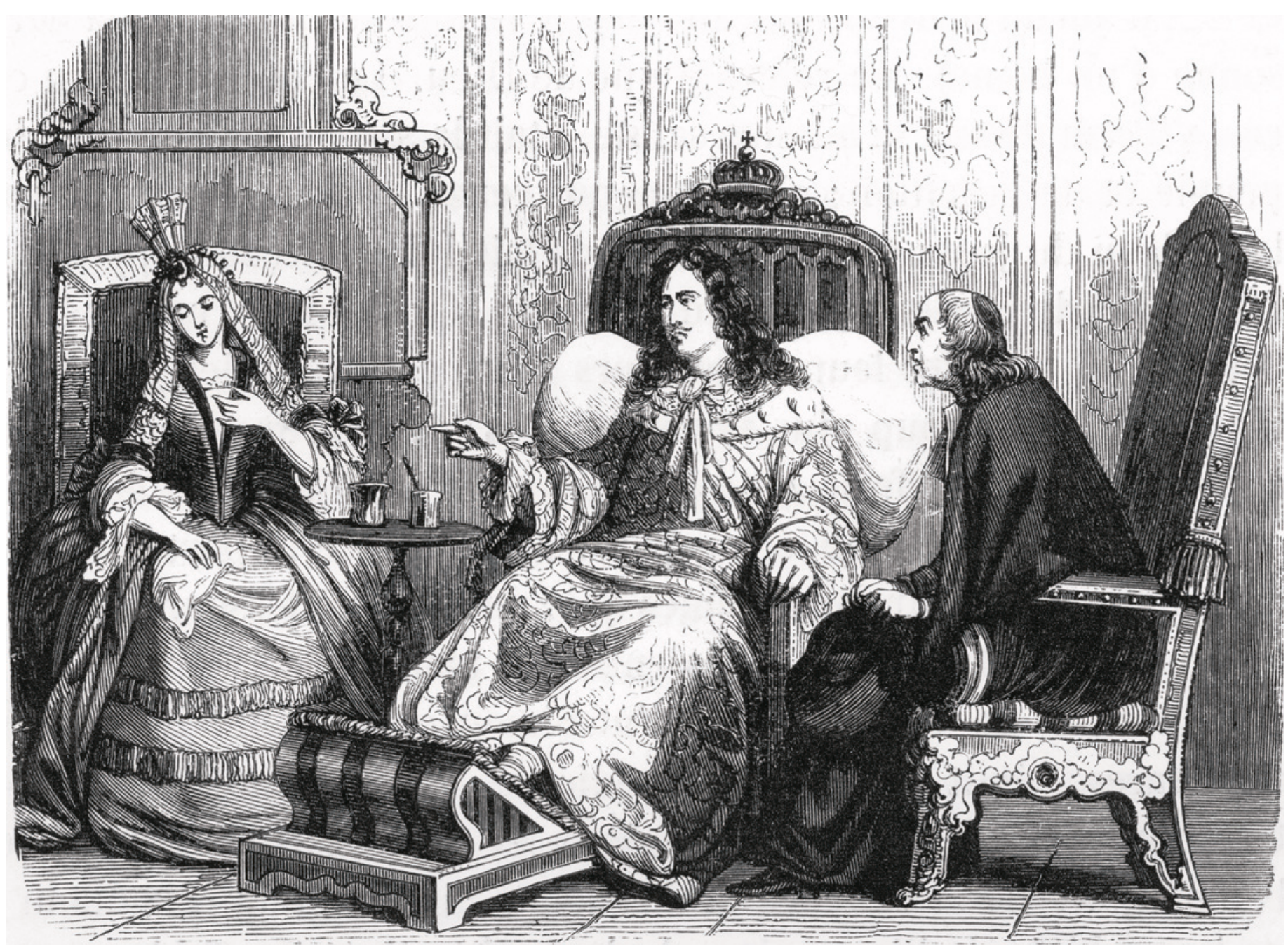

Figur 1 Hustruen Mme de Maintenon og skriftefaren père La Chaise med den plagede Ludvig 14. Tresnitt. Illustrasjon: AKG Images/scanpix

måneder han fikk eksperimentere. Han var spesielt opptatt av å finne frem til riktig type instrument. Etter hvert utviklet han selv det instrumentet som ble brukt på Solkongen, kalt «le bistouri royal» (den kongelige sonde). Dette var en lang svunget sonde i sølv, som i dag er utstilt på det medisinhistoriske museet i rue de l'École de Medécine (medisinerskolegaten) i Paris (fig 2).

\section{Operasjonen}

Dagen før operasjonen inspiserte Solkongen sine hageanlegg (fig 3), overvåket de pågående arbeider, spiste sitt kveldsmåltid sammen med sin familie og - etter nok en runde med utålelige smerter - tok han den endelige beslutning om å la seg operere dagen etter. 18. november 1686 klokken syv om morgenen ble Hans Majestet ledsaget inn i le salon de Bassans (som den het før ombyggingen i 1701, dette tilsvarer i dag le salon de l'Oeil de Boeuf (okseøyesalongen), forværelse til kongens soverom).
De innviede var allerede på plass. Hans leger, førstelege Antoine Daquin og dennes etterfølger, Guy Crescent Fagon (16381718), førstekirurg Félix samt fire apotekere var ankommet rommet allerede klokken fem om morgenen gjennom forskjellige dører for ikke å vekke mistanke. Kongen hadde fått et preoperativt klyster. Han virket til å ha nervene under kontroll og viste før inngrepet tok til stor interesse for de ulike instrumentene som skulle benyttes.

Så ble han lagt på en seng med ansiktet mot vinduet. Under magen fikk han en pute mens lårene ble spredt og holdt oppe av to apotekere. Mot slutten av operasjonen spurte han: «Er det gjort, mine herrer? Avslutt. Behandle meg ikke som en konge, jeg vil bli frisk som om var jeg bonde» (4).

Denne, det syttende århundres store operasjon, ble kun verdiget én setning, riktignok på en halv side, i kongens helsejournal (3). Aller helst ville nok Daquin, med sin nedlatende holdning til kirurger, ha unnlatt å nevne episoden i det hele tatt. Han fikk i hvert fall med at det også ble utført en årelating.

At operatøren selv, Félix, følte trang til en mer utførlig beskrivelse av denne spektakulære operasjonen, er mer forståelig. Dagen etter skrev han hele 18 sider. Hvor dette dokumentet er blitt oppbevart siden, vites ikke, men i 2007 dukket papirene opp igjen og ble lagt ut på auksjon med utropspris 4000 euro (7). Antagelig ble den endelige prisen, med nåtidens store interesse for kongerelaterte gjenstander, mye høyere.

Den tre timer lange operasjonen ble foretatt uten noen form for bedøvelse. Krigsminister Louvois holdt pasienten $\mathrm{i}$ hånden under hele inngrepet, mens Mme de Maintenon sto ved kaminen. Kongen skal ikke ha klaget over smerte, men skal ved to anledninger ha utbrutt «Mon Dieu». Smertene må ha vært uutholdelige, men Ludvig måtte holde masken for sin egen og sitt lands verdighets skyld.

Og kongen ikke bare overlevde - operasjonen må benevnes som en suksess, for han 


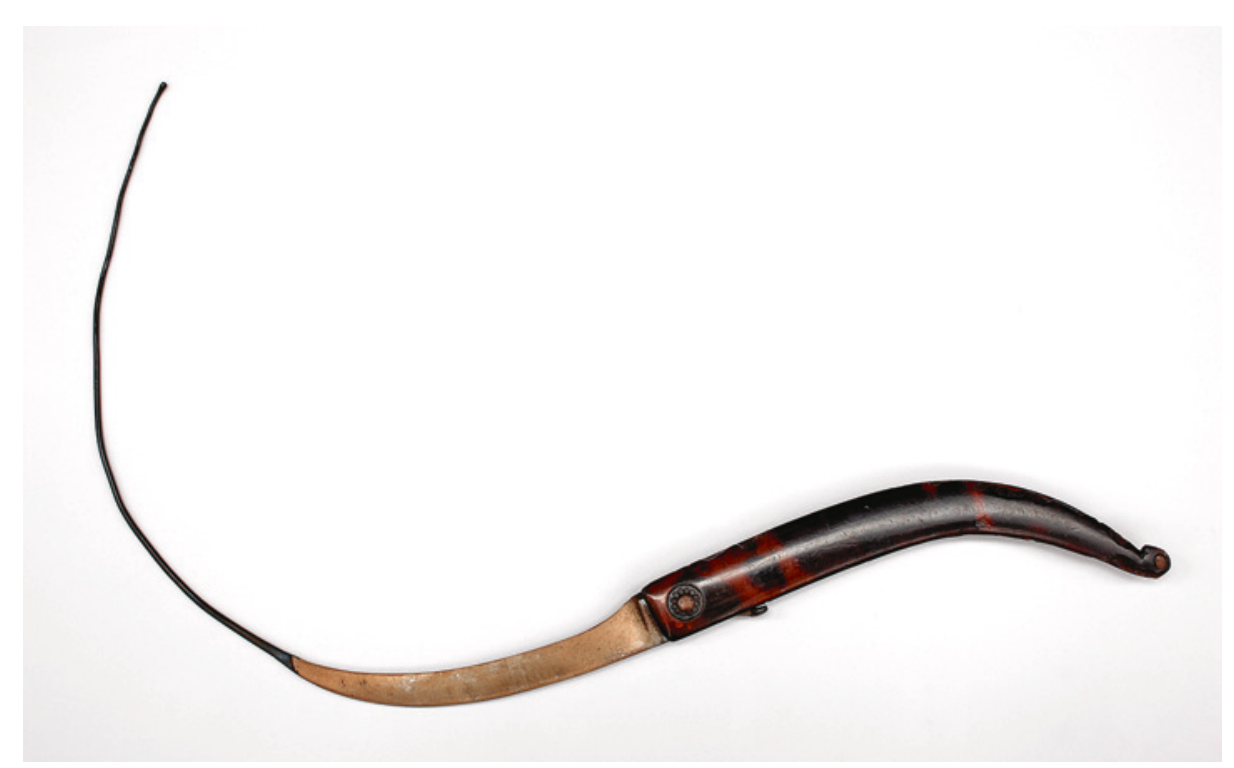

Figur 2 Dette er instrumentet - en skalpell med kongelig kurvatur - som ble utviklet for å operere Ludvig 14. Foto: Musée d'Histoire de la Médecine, Paris

ble helbredet. Riktignok måtte han reopereres to ganger, men etter den første store operasjonen var han naturlig nok svært lettet og glad. Klokken ti var nyheten spredt på slottet og kongen selv holdt råd fra sin seng $\mathrm{og}$ «synger hele dagen i sengen og er i overraskende godt humør» (4). Han var på bena allerede to dager senere.

\section{En modig konge}

Ludvig 14 utviste stort mot ved å la seg operere. Vel var han presset opp i et hjørne - han hadde vel egentlig ikke noe valg, verken politisk eller personlig. Frankrike var i 1686 i en vanskelig situasjon, isolert og forhatt og med de aller fleste europeiske land $\mathrm{i}$ allianse mot seg (den augsburgske liga) (8).

Et kirurgisk inngrep var siste utvei, og avgjørelsen ble ikke tatt før etter måneders forsøk med andre og mislykkede behandlinger. For Ludvig, som man vet var redd for mindre kirurgiske inngrep som årelating $(3,4)$, var nok dette en tung beslutning. At han hadde mot til å gjennomgå en så omfattende og potensielt farlig operasjon (blødningsfare) uten bedøvelse, må betegnes som stort.

\section{Konsekvenser av operasjonen}

Fisteloperasjonen fikk mange konsekvenser. Kirurgens innsats ble belønnet med en adelstittel, et slott og store pengegaver (9). For alle med fistler betydde operasjonen et håp om bedring, og som alt annet som Solkongen gjorde, skapte også dette mote i Versailles. Hoffet sto i kø for å få utført det samme inngrepet, med eller uten fistel. De uten fistel ble avvist av kirurgene (9).
Kongens død førte til større anseelse for kirurgene, da man skjønte at de kanskje kunne har reddet hans liv dersom de hadde fått amputere tidlig i forløpet (2).

\section{Utviklingen av fransk kirurgi}

Solkongen ga ved sin makt og innflytelse kirurgien uavhengigheten tilbake. Han sørget blant annet for at det ble opprettet en lærestilling i kirurgi ved Le Jardin du Roi (kongens hage), nå Jardin des plantes, i 1671, for å bedre opplæringen av kirurger. Han måtte ofte blande seg i krangler mellom det mektige medisinske fakultet i Paris og sine egne leger.

Å være kongens førstekirurg var å inneha det øverste kirurgiske embetet i landet (12). Paris-fakultet hadde alltid vært kritisk innstilt til kongens leger og likte dårlig det omdømmet kirurgene etter hvert fikk ved hoffet $(2,9)$. Med dekanus i spissen gikk de til og med til fysisk angrep på dem (9). Det medisinske fakultet i Paris var kjent for å være bakstreversk og kjempet imot opplysningstidens nye ideer (2).

Etter Ludvig 14s død gjennomførte de tre påfølgende kongelige førstekirurger Mareschal, François Gigot de La Peyronie (1678-1747) og Germain Pichault de La Martinière (1697-1783) - en serie med reformer. Den første omfattet reorganisering av kirurgiutdanningen. Den opplæringen som ble gitt i regi av det medisinske fakultetet, var lite verdt. De som ønsket å bli gode kirurger fulgte ikke denne undervisningen, de gikk heller i lære hos erfarne kirurger.

Den første offisielle kirurgiutdanningen ble opprettet i 1724 ved lærestedet SaintCôme (13). Det medisinske fakultet gjorde gjentatte forsøk på å tilegne seg kontrollen, men uten hell. La Peyronie og La Martinière etablerte etter hvert flere undervisningsinstitusjoner (14). Den viktigste nyskapningen var opprettelsen av det kongelige akademi for kirurgi (L'Académie royale de Chirurgie) i 1731 (13), med støtte fra Ludvig 15 og hans førstelege (indremedisiner) Pierre Chirac (1650-1732). Det hører med til historien at et tilsvarende kongelig akademi for medisin, ønsket av den samme livlege Chirac, ikke så dagens lys fordi Chirac døde for tidlig til å kunne kjempe mot den innbitte motstanden fra det medisinske fakultet.

Etableringen av kirurgiakademiet ble umiddelbart en suksess, og det nøt stor anseelse. Det eksisterte i 62 år og fostret mange berømte kirurger. Som Voltaire skrev: «Fremskrittene innen kirurgien kom så raskt og var så oppsiktsvekkende i dette århundret at man kom til Paris fra alle verdens kanter for å bli operert og kurert. Ikke bare var det kun i Frankrike det fantes utmerkede kirurger, men det var også kun 


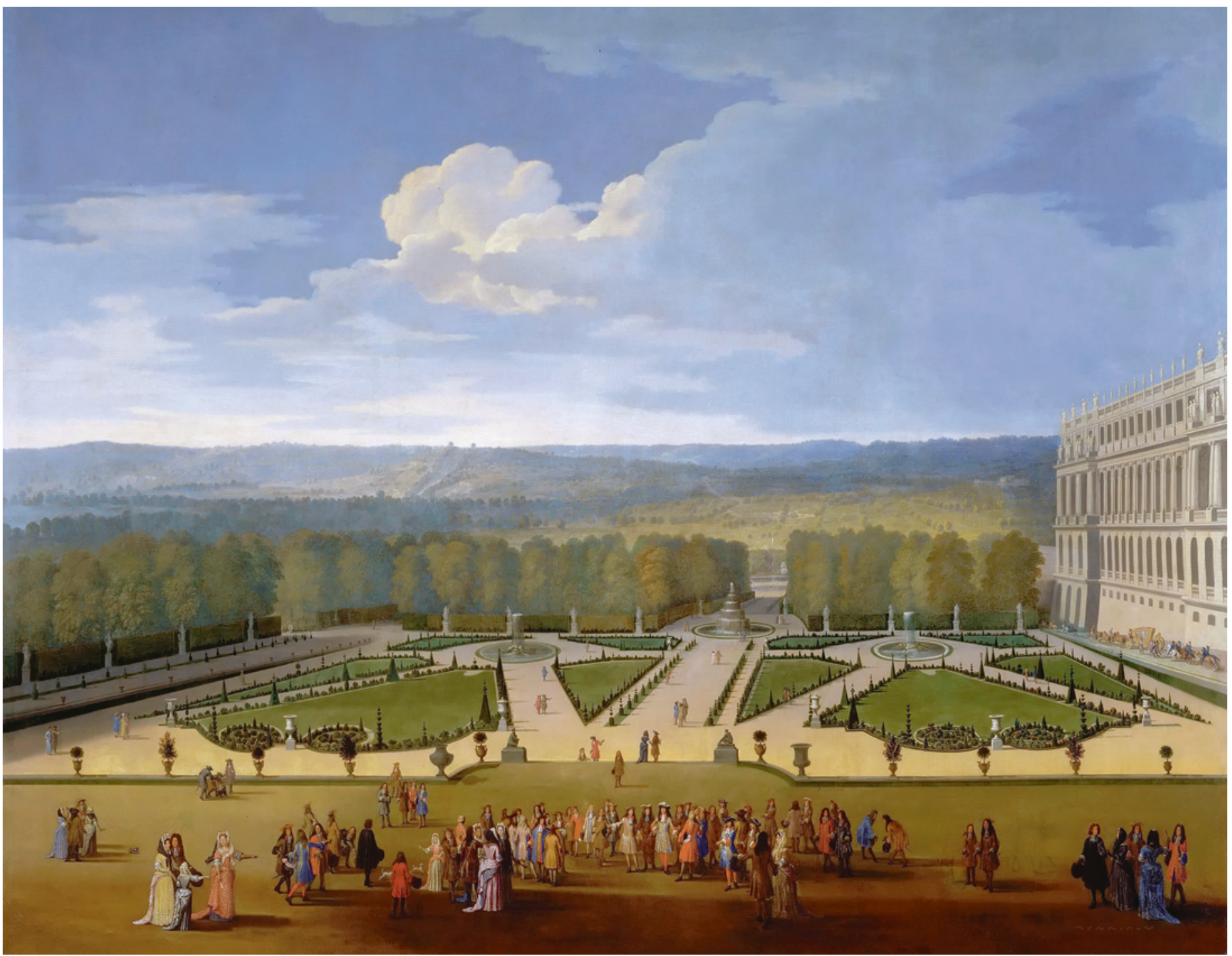

Figur 3 Ludvig 14 og hoffet spaserer i parken i Versailles. Fra Musée de l'Histoire de France, Château de Versailles. Illustrasjon: Heritage/scanpix

i dette landet at de nødvendige instrumenter ble laget» (13).

Med den store revolusjonen i 1789 ble alle akademiene avviklet. Og den følgende turbulente perioden i fransk historie, med keiserdømmet, restaurasjon av kongemakten og republikker, ble helt til opprettelsen av den nye foreningen for kirurgi i Paris i 1843 for kirurgien en periode uten akademisk utvikling, men ikke uten kirurgi (13). Det ble opprettet medisinske utdanningsinstitusjoner i Paris, Montpellier og Strasbourg for å erstatte de rene kirurgiskolene. Dette viste viljen til en felles basis for medisinerundervisningen, en kombinasjon av medisin og kirurgi, under tydelig innflytelse av opplysningsfilosofen og forfatteren Dide$\operatorname{rot}(1,13)$.

Napoleon forhindret en ny splittelse av medisin og kirurgi ved å forby en uavhengig organisasjon av kirurger (13). I 1808, under reorganiseringen av hele universite- tet, reetablerte man så det medisinske fakultet, med undervisning $\mathrm{i}$ både medisin og kirurgi (13). Disse to store fagene var endelig blitt sidestilt i en akademisk ramme.

\section{Ellen Jørum (f. 1954)}

er dr.med., spesialist i klinisk nevrofysiologi og i nevrologi, seksjonsoverlege og professor. Forfatter har fylt ut ICMJE-skjemaet og oppgir ingen interessekonflikter.

\section{Litteratur}

1. Haave P. Medisinens kirurgisering og etableringen av en norsk legeskole i 1814. Tidsskr Nor Legeforen 2009; 129: 2637-41.

2. Gelfand T. Professionalizing modern medicine. Paris surgeons and medical science and institutions in the 18th century. London: Greenwood Press, 1980.

3. Perez S. Journal de santé de Louis XIV. Paris: Jérôme Milion, 2004

4. Perez S. La santé de Louis XIV. Lyon: Éditions Champ Vallon, 2007.
5. Caroly M. Le corps du Roi-Soleil. Paris: Éditions de Paris, 1990

6. Girard G. Mémoires du curé de Versailles, Francois Hébert, 1686-1704. Paris: Les Éditions de France, 1927

7. Jørum E. Les médecins de Louis XIV. Masteroppgave. Oslo: Universitetet i Oslo, 2008.

8. Goubert P. Louis XIV et vingt millions de Français. Paris: Librairie Arthème Fayard, 1966.

9. Millepierres F. La vie quotidienne des médecins au temps de Molière. Paris: Hachette, 1964

10. Ullmann JA. Saint-Simon et la médecine. Paris Éditions Glyphe, 2012.

11. Perez S. La mort des rois. Paris: Jérôme Million, 2006

12. Lunel A. La maison médicale du roi: Lyon: Éditions Champ Vallon, 2008

13. Chatelain C. Histoire de l'Académie Nationale de Chirurgie. e-mémoires de l'Académie Nationale de chirurgie 2006; 5: 18-23

14. Iselin F. La Martinière, chirurgien de Louis XV Paris: Perrin, 2010.

Mottatt 8.3. 2015, første revisjon innsendt 15.9. 2015, godkjent 22.4. 2016. Redaktør: Ketil Slagstad.

Publisert først på nett. 